\title{
Making computed tomographic screening accessible for all
}

\author{
Jessica S. Donington, MD, MSCR
}

\author{
From the Department of Cardiothoracic Surgery, NYU School of Medicine, New York, NY. \\ Disclosures: Author has nothing to disclose with regard to commercial support. \\ Received for publication Jan 2, 2018; accepted for publication Jan 6, 2018; available ahead of print Feb 8, 2018. \\ Address for reprints: Jessica S. Donington, MD, MSCR, Department of Cardiothoracic Surgery, NYU School of \\ Medicine, 530 1st Ave, Suite 9V, New York, NY 10016 (E-mail: Jessica.donington@nyumc.org). \\ J Thorac Cardiovasc Surg 2018;155:2682 \\ $0022-5223 / \$ 36.00$ \\ Copyright $(\subset) 2018$ by The American Association for Thoracic Surgery \\ https://doi.org/10.1016/j.jtcvs.2018.01.003
}

Despite the demonstrated efficacy of low-dose computed tomographic (LDCT) screening to reduce lung cancer mortality in high-risk populations, widespread implementation has been slow. Minorities and the uninsured are at particular risk for decreased access to specialty medical care and prone to delays in the diagnosis and treatment of lung cancer. These cohorts have limited access and underutilization of lung cancer screening. ${ }^{1}$ Improving access to LDCT screening for these vulnerable subgroups may facilitate closure of this disparity gap and improve survival for patients with early-stage lung cancer. Poor engagement of primary care physicians is an important reason for slow implementation largely due to knowledge gaps regarding screening guidelines, insufficient counseling time, and poor "buy in" regarding screening benefit. ${ }^{2}$

Institutional commitment and required infrastructure to establish and maintain a LDCT screening program is daunting for financially strapped health systems and an additional culprit in the disparity gap. A recent US Department of Veterans Affairs survey noted that only $61.5 \%$ of pulmonologists agreed with the indications for LDCT screening and cited costs and effort associated with developing a screening program as major barriers to implementation. ${ }^{3}$ The work in this issue of the Journal from Steiling and colleagues ${ }^{4}$ at the Boston Medical Center provides early evidence for establishment of a successful screening program in a health care system that cares primarily for minorities and the uninsured. They demonstrated safe and timely evallignant risk. They provide a guide of required organizational resources for others to follow and highlight the key role of a dedicated midlevel practitioner to ensure appropriate screening selection, adherence, counseling, and education of patients and referring physicians. uation and interventions for screened nodules with high ma-

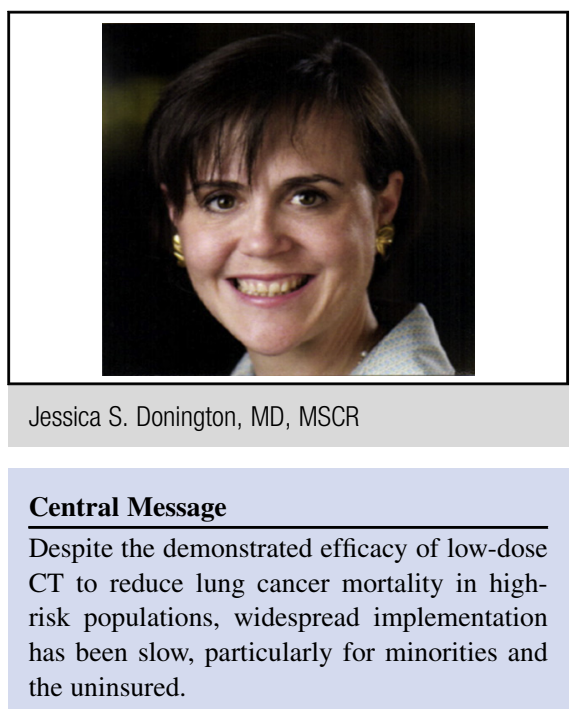

See Article page 2674.
It is not enough simply to establish the benefits of LDCT screening for lung cancer; we also need to make it available to all high-risk individuals, including the poor and uninsured. Early-stage lung cancer is a surgical disease, and thoracic surgeons should take the lead in this effort. The benefits of LDCT screening can only be appreciated in a multidisciplinary program with active thoracic surgical engagement. Thoracic surgeons need to advocate locally and nationally for the resources to implement LDCT screening properly, so that it is accessible by all.

\section{References}

1. Jacobsen MM, Silverstein SC, Quinn M, Waterston LB, Thomas CA, Benneyan JC, et al. Timeliness of access to lung cancer diagnosis and treatment: a scoping literature review. Lung Cancer. 2017;112:156-64.

2. Raz DJ, Wu GX, Consunji M, Nelson RA, Kim H, Sun CL, et al. The effect of primary care physician knowledge of lung cancer screening guidelines on perceptions and utilization of low-dose computed tomography. Clin Lung Cancer. 2018; 19:51-7.

3. Iaccarino JM, Clark J, Bolton R, Kinsinger L, Kelley M, Slatore CG, et al. A national survey of pulmonologists' views on low-dose computed tomography screening for lung cancer. Ann Am Thorac Soc. 2015;12:1667-75.

4. Munoz-Largacha JA, Steiling KA, Kathuria H, Charlot M, Fitzgerald C, Suzuki K, et al. Initial experience following implementation of lung cancer screening at an urban safety net hospital. J Thorac Cardiovasc Surg. 2018;155:2674-81. 